\title{
Knowledge on primary and secondary prevention of asthma among caregivers of asthmatic children admitted to paediatric wards in Gampaha District
}

\author{
Niranjala Perera ${ }^{1}$ \& Chrishantha Abeysena ${ }^{2 *}$ \\ 'Postgraduate Institute of Medicine, University of Colombo, Sri Lanka; ${ }^{2}$ Department of Public Health, Faculty \\ of Medicine, University of Kelaniya, Sri Lanka \\ *Correspondence: chrishantha-abeysena@kln.ac.lk (iD) https://orcid.org/0000-0001-5456-8281
}

DOI: https://doi.org/10.4038/jccpsl.v25i2.8190

Received on: 19 December 2018

Accepted on: 29 May 2019

\begin{abstract}
Introduction: Asthma is considered to be one of the major public health problems. The accurate knowledge of caregiver on asthma is important for the management.

Objectives: To describe the knowledge on primary and secondary prevention of asthma among caregivers of asthmatic children admitted to the paediatric wards in the district of Gampaha

Methods: A descriptive cross-sectional study was carried out among 577 caregivers of inward asthmatic children. Pre-tested interviewer- and self-administered questionnaires were used to assess the knowledge on asthma. The grand score of knowledge on asthma was calculated out of 34 . The $75^{\text {th }}$ percentile value was considered to differentiate 'good' knowledge from 'poor' knowledge. Multiple logistic regression was applied to determine the factors associated with poor knowledge on asthma. Results were expressed in adjusted odds ratio (aOR) and 95\% confidence interval (CI).
\end{abstract}

Results: The mean score for knowledge on asthma was 20.6 ( $\mathrm{SD}=4.42$ ) ranging from 7 to 30 . Among the caregivers, 369 (64\%) had poor knowledge on asthma. Low educational level of the caregiver $(\mathrm{aOR}=2.48 ; 95 \% \mathrm{CI}=1.59,3.86)$ and being under prophylaxis treatment for less than one year $(\mathrm{aOR}=2.49 ; 95 \% \mathrm{CI}=1.50,4.13)$ were the determinants of poor knowledge on asthma.

Conclusions: Majority of the caregivers' knowledge on asthma was poor. The caregivers' low educational level and shorter duration of prophylaxis treatment for the children were associated with poor knowledge on asthma.

Key words: asthma, children, caregiver, knowledge, paediatrics, prevention 


\section{Introduction}

Asthma is considered to be one of the major public health problems in the country and Sri Lanka is identified as one of the highest prevalent countries with asthma (1). Disease of the respiratory tract is the second commonest cause for hospital admissions in the country (2). Hospital admission rates have increased from 555 per 100,000 in 1990 to 930 per 100,000 in 2002 (2).

Although asthma cannot be cured, high quality management can control the disease and facilitate children to gain good quality of life. High quality management also includes secondary prevention measures to avoid asthma triggers that irritate and inflame the airways. One of the programme objectives of the World Health Organization for prevention and control of asthma is 'primary prevention to reduce the level of exposure to common risk factors, particularly tobacco smoke, frequent lower respiratory infections during childhood and air pollution (indoor, outdoor, and occupational exposure)' (3).

Main predisposing risk factors for developing asthma are the exposure to inhaled substances and genetic susceptibility. Inhaled substances include indoor allergens such as house dust mites in bedding, stuffed toys and carpets, indoor air pollution and pet dander, outdoor allergens especially pollen and moulds, active or passive tobacco smoke, chemical fumes and outdoor air pollution. Also, extreme emotional arousal by means of anger or sorrow, cold air, allergic food and physical exercise, and medications like aspirin and other non-steroid anti-inflammatory drugs trigger asthma (3). The risk factors and triggers may differ among individual children. Therefore, it is important for the caregiver to obtain considerable knowledge to identify the risk factors specific for individual child and avoid them as secondary preventive strategies to control asthma attacks. Also, caregivers have different beliefs on triggering agents, and therefore due to overprotectiveness, they restrict nutritious food items such as milk and eggs from all children with asthma irrespective of the individual triggering agent. Furthermore, it is necessary for the caregiver to be knowledgeable about the importance of continuing prophylactic medication while proper training should be given for handling inhaler devices to control asthma effectively.
Though the associated factors have been identified, the knowledge of caregiver on asthma has not been described in Sri Lanka. Moreover, how knowledgeable the caregiver is in identifying the triggering factors has not been studied in the local context, and therefore a need exists to study caregiver' knowledge on risk factors of asthma. Findings of such a study will enable the healthcare provider to emphasis on areas where the caregiver's knowledge has to be improved for betterment of the child. Therefore, the objective of this study was to describe the knowledge on primary and secondary prevention of asthma among caregivers.

\section{Methods}

A descriptive cross-sectional study was carried out in paediatric wards in four hospitals namely Colombo North Teaching Hospital Ragama (CNTH), District General Hospital Gampaha (DGHG), District General Hospital Negombo (DGHN) and Base Hospital Wathupitiwala (BHW). The study population was the caregivers with children aged 2-12 years with asthma, admitted to the paediatric wards. The exclusion criteria were caregivers who had not lived in the same household as the child during past six months.

The sample size was calculated assuming the poor knowledge on asthma as $50 \%$ and precision as $5 \%$, and the required number was 384 caregivers. The caregivers were selected from the paediatric wards, which were considered as clusters, and therefore a cluster effect of 2.5 was added and the final sample size was 577 caregivers. All the caregivers who were eligible and willing to participate were recruited for the study, from all paediatric wards of the four hospitals from the commencement of the study until the sample size was fulfilled.

An interviewer-administered questionnaire was used to assess the basic demographic data of the caregiver and a self-administered questionnaire to assess the caregiver knowledge on asthma under four components. The four components were general knowledge about asthma, knowledge on risk factors (primary prevention) of asthma, knowledge on secondary prevention (early diagnosis and treatment) and treatment seeking behaviour, and knowledge on disregarding myths with relevance to inhaler drugs. The knowledge questionnaire was constructed based 
on international studies (4-6) and a Sri Lankan study (7). Furthermore, content in the chapter "What patient should know about asthma" in guidelines published by the College of Paediatricians of Sri Lanka (8) was used in developing the questionnaire. The final questionnaire was formulated after assessing the face validity and the content validity of the questions by the experts. Also, the weights of the marks for each component in part was discussed and concluded according to the expert opinion. Trained four pre-intern medical graduates were used as research assistants to collect data.

General knowledge on asthma was assessed by four questions, giving each a single mark. Grand score for knowledge on primary prevention of asthma was scored out of 17 marks for five questions: knowledge on risk factors for childhood asthma to progress in to adulthood (5 marks); knowledge on common risk factors for asthma (5 marks); knowledge on the protective effect of exclusive breast feeding for six months (1 mark); knowledge on common triggering factors for asthma (5 marks); and knowledge on most important area of the house to be free of triggering factors (1 mark). Grand score for knowledge on secondary prevention on asthma was scored out of nine marks for five questions: knowledge on secondary prevention and treatment seeking behaviour of caregiver further included, knowledge on common symptoms of asthma (4 marks), common activities that children can do as normal children when asthma is controlled with medication ( 2 marks) and knowledge on treatment of asthma (3 marks). The knowledge on disregarding myths about inhaled drugs was scored out of four marks.

The questionnaire was pre-tested among ten caregivers who attended for treatment for their child's asthma attack at paediatric wards in the CNTH. The reliability was assessed by means of test re-test method. Twenty caregivers were selected from all four hospitals. The self-administered questionnaire was administered to caregivers at two weeks follow-up clinic visit. The selected variables were assessed using Kappa coefficient and results displays the minimum score of 0.68 and good agreement.

\section{Data analysis}

Data entry and analysis were done by using Statistical Package for Social Sciences (SPSS) version
16. All data entered was rechecked for accuracy. The mean score for each component of knowledge on asthma was calculated. The mean of the grand score was calculated out of 34 . The grand score on knowledge on asthma was converted to percentage values and $>75^{\text {th }}$ percentile was considered as 'good' knowledge. The bivariate and multivariable logistic regression were performed, and the results were expressed as adjusted odds ratio (aOR) and 95\% confidence interval (CI). The Hosmer and Lemeshow test chi-square value of the final model was 0.72 with $\mathrm{p}$ value of 0.91 , which indicated adequate goodness of fit of the final model.

\section{Results}

A total of $149(25.8 \%)$ caregivers were recruited from CNTH, 148 (25.6\%) from BHW, 142 (24.6\%) from DGHN and 138 (23.9\%) from DGHG. The vast majority of the caregivers were mothers of the children $(n=513 ; 92 \%)$ followed by grandmothers $(n=34$; $5.9 \%)$ and others $(n=12 ; 2.1 \%)$. The majority of caregivers $(n=260 ; 45.1 \%)$ had studied up to GCE Ordinary Level $(\mathrm{O} / \mathrm{L})$ or had 11 years of schooling. Sixteen $(2.8 \%)$ had an educational level beyond GCE Advanced Level (A/L) or above 13 years of schooling while there were $12(2.1 \%)$ with an education level less than five years of schooling. When considering the total study population of caregivers, 395 (78.5\%) had passed GCE O/L.

The highest percentage (89.9\%) of caregivers had correctly known that asthma is a disease of the lungs while only $36 \%$ had known that asthma is a disease which could be controlled with medication (Table 1). 105 (18.2\%) scored four marks, 262 (45.4\%) three marks, $190(32.9 \%)$ two marks and only 20 (3.5\%) one mark for general knowledge on asthma.

As much as $85.3 \%$ knew that childhood asthma with parental smoking as a risk factor could progress into adulthood, but $71.7 \%$ of caregivers had the misconception that consuming excessive amounts of eggs in childhood could also progress to adulthood asthma (Table 1). The knowledge on persisting risk factors was scored out of five marks. Only 24 (4.2\%) caregivers scored all five marks, whereas 112 (19.4\%) scored four marks; $21(37.6 \%)$ scored three marks; 137 (23.7\%) scored two marks; 57 (9.9\%) scored one mark; and $30(5.2 \%)$ scored no marks at all. 
Most of the caregivers knew that having pets in the house $(93.4 \%)$ and indoor air pollution $(90.3 \%)$ are common risk factors for asthma, whereas $67.6 \%$ had the erroneous idea that low birth weight was a risk factor (Table 1). 118 (20.5\%) scored all five marks; 164 (28.4\%) scored four marks; and 214 (37.1\%) scored three marks for knowledge on common risk factors for asthma. Only $61(10.6 \%)$ scored two marks; $16(2.8 \%)$ scored one mark; and $4(0.7 \%)$ no score at all.

Assessing knowledge on common triggering factors, $95.5 \%$ scored correctly for change in temperature but scored less for emotions (40.2\%) (Table 1). About a quarter $(27.4 \%)$ scored all five marks; 259 (44.9\%) scored four marks; 105 (18.2\%) scored three marks; 21 (3.6\%) scored two marks; and 31 (5.4\%) scored one mark; and $3(0.5 \%)$ no marks at all.

Table 1. Distribution of the caregivers' knowledge on asthma and risk factors $(N=577)$

\begin{tabular}{llllll}
\hline Statement & \multicolumn{2}{c}{ Correct } & \multicolumn{2}{c}{ Incorrect } \\
\cline { 2 - 5 } & No. & $\%$ & No. & $\%$ \\
\hline
\end{tabular}

\section{General knowledge on asthma}

- Asthma is a disease of lungs

$\begin{array}{rrrr}519 & 89.9 & 58 & 10.1 \\ 373 & 64.6 & 204 & 35.4 \\ 208 & 36.0 & 369 & 64.0\end{array}$

- Asthma is a disease which could be controlled with medication

$\begin{array}{lll}506 & 87.7 \quad 71\end{array}$

12.3

\section{Risk factors for childhood asthma to progress} into adulthood

- Frequent symptoms in first year of life

$\begin{array}{lrrr}254 & 44.0 & 323 & 56.0 \\ 227 & 39.3 & 350 & 60.7 \\ 414 & 71.8 & 163 & 28.2 \\ 167 & 28.9 & 410 & 71.1 \\ 492 & 85.3 & 85 & 14.7\end{array}$

\section{Risk factors for asthma}

- Low birth weight

187

- Indoor air pollution by firewood

- Smoking within the house

- Teenage pregnancy

- Pets in the house

\section{Common triggering factors for asthma}

- Viral infection

$\begin{array}{rrrr}431 & 74.7 & 146 & 25.3 \\ 510 & 88.4 & 67 & 11.6 \\ 232 & 40.2 & 345 & 59.8 \\ 490 & 84.9 & 87 & 15.1 \\ 551 & 95.5 & 26 & 4.5\end{array}$


The majority (94.3\%) had knowledge that wheezing noise from the chest was a common symptom. Nevertheless, $58.1 \%$ had the erroneous thought that fever was a common symptom of asthma (Table 2). Further, 130 (22.5\%) scored four marks; $310(53.7 \%)$ scored three marks while $100(17.3 \%)$ scored two marks; and 37 (6.4\%) scored one mark. Over half had the knowledge that bathing (59.3\%) and playing or swimming $(51.1 \%)$ could be done as a normal child when asthma is controlled with medication (Table 2). Therefore, 263 (45.6\%) scored two marks; $111(19.2 \%)$ scored one mark; and 203 (35.2\%) caregivers scored zero marks. Only $35.4 \%$ of the caregivers were able to name a reliever medication correctly; $17.3 \%$ to name side effect of reliever drug; and $18 \%$ to name an asthma controller drug which is used for longer durations (Table 3). Only 55 (9.5\%) answered all three correctly; 81 (14\%) scored two marks; 81 (14\%) scored one mark; and $62.4 \%$ did not get any mark.

Only $52.9 \%$ caregivers knew that inhaler drugs need smaller doses compared to oral drugs to relieve symptoms but $61.2 \%$ had the misconception that inhaler drugs cause more side effects in the child (Table 2). Four, three, two, one and zero marks were scored by $19.6 \%, 12.5 \%, 23.6 \%), 20.1 \%$ and $24.3 \%$ for disregarding myths on inhaler drugs.

Out of the overall score on asthma knowledge of 34 , mean score for knowledge on asthma was 20.63 $(\mathrm{SD}=4.42)$ and ranged from 7 to 30 . Only $208(36 \%)$ caregivers had good knowledge on asthma and 369 (64\%) had poor knowledge.

Table 2. Distribution of the caregivers' knowledge on primary and secondary prevention for asthma $(\mathrm{N}=577)$

\begin{tabular}{llrrr}
\hline Statement & \multicolumn{2}{c}{ Correct } & \multicolumn{2}{c}{ Incorrect } \\
\cline { 2 - 5 } & No. & $\%$ & No. & \% \\
\hline Common symptoms of asthma & & & & \\
- Night cough & 489 & 84.7 & 88 & 15.3 \\
- Cold & 412 & 71.4 & 165 & 28.6 \\
- Wheezing noise from chest & 544 & 94.3 & 33 & 5.7 \\
- Fever & 242 & 41.9 & 335 & 58.1 \\
\hline Activities could be engaged when asthma is controlled & & & & \\
- Bathing & 342 & 59.3 & 235 & 40.7 \\
- Playing or swimming & 295 & 51.1 & 282 & 48.8 \\
\hline Knowledge on treatment of asthma & & & & \\
- Name a drug that could be used as a reliever & 204 & 35.4 & 373 & 64.6 \\
$\quad$ medication with an episode of asthma & & & & \\
- Name a side effect of above drug & 100 & 17.3 & 477 & 82.7 \\
- Name a drug that could be used to control & 104 & 18.0 & 473 \\
$\quad$ asthma and need to be taken for a long period & & & & \\
\hline Inhaled drugs when compared to oral drugs & & & & \\
- Needs a smaller dose to relieve the symptoms & 305 & 52.9 & 272 & 47.1 \\
- Cause more side effects & 224 & 38.8 & 353 & 61.2 \\
- Can deliver the drug directly to the lung & 385 & 66.7 & 192 & 33.3 \\
- Not good for the patient if used for long period & 142 & 24.6 & 453 & 75.4 \\
\hline
\end{tabular}


Table 3. Association of the caregivers' knowledge on asthma with their socio-demographic characteristics $(N=577)$

\begin{tabular}{|c|c|c|c|c|c|c|}
\hline \multirow{3}{*}{ Characteristics } & \multicolumn{4}{|c|}{ Knowledge on asthma } & \multirow{3}{*}{$\begin{array}{c}\text { Odds Ratio } \\
95 \% \mathrm{CI}\end{array}$} & \multirow{3}{*}{$\begin{array}{c}\text { p } \\
\text { value }^{2}\end{array}$} \\
\hline & \multicolumn{2}{|c|}{ Poor } & \multicolumn{2}{|c|}{ Good } & & \\
\hline & No. & $\%$ & No. & $\%$ & & \\
\hline \multicolumn{7}{|l|}{ Type of caregiver } \\
\hline Other caregivers & 34 & 73.9 & 12 & 26.1 & 0.97 & 0.94 \\
\hline Mother & 395 & 74.4 & 136 & 25.6 & $0.49-1.93$ & \\
\hline \multicolumn{7}{|l|}{ Age of caregiver } \\
\hline$<30$ years & 162 & 81.8 & 36 & 18.2 & 1.88 & 0.003 \\
\hline$\geq 30$ years & 267 & 70.4 & 112 & 29.6 & $1.24-2.88$ & \\
\hline \multicolumn{7}{|l|}{ Sex of the child } \\
\hline Male & 219 & 76.3 & 68 & 23.7 & 1.22 & 0.28 \\
\hline Female & 210 & 72.4 & 80 & 27.6 & $0.84-1.78$ & \\
\hline \multicolumn{7}{|l|}{ Ethnicity } \\
\hline Non-Sinhalese & 44 & 75.9 & 14 & 24.1 & 1.09 & 0.78 \\
\hline Sinhalese & 385 & 74.2 & 134 & 25.8 & $0.58-2.05$ & \\
\hline \multicolumn{7}{|l|}{ Educational level $^{1}$} \\
\hline$<$ GCE O/Level & 316 & 80.0 & 79 & 20.0 & 2.44 & 0.001 \\
\hline$>$ GCE O/Level & 113 & 62.1 & 69 & 37.9 & $1.65-3.6$ & \\
\hline \multicolumn{7}{|c|}{ Occupation of mothers } \\
\hline Housewife & 305 & 76.4 & 94 & 23.6 & 1.41 & 0.08 \\
\hline Paid occupation & 124 & 69.7 & 54 & 30.3 & $0.95-2.09$ & \\
\hline \multicolumn{7}{|c|}{ Income per person (Rupees) } \\
\hline$<5000$ & 210 & 78.4 & 58 & 21.6 & 1.48 & 0.04 \\
\hline$\geq 5000$ & 219 & 70.9 & 90 & 29.1 & 1.02-2.17 & \\
\hline
\end{tabular}

${ }^{1}$ General Certificate of Education (Ordinary Level); ${ }^{2} \mathrm{p}$ value at 0.05 significance level

Of the socio-demographic factors (Table 3), caregivers' age less than thirty years, education below Ordinary Level and monthly income less than Rs.5000.00 were significantly associated with poor knowledge on asthma. Of the characteristics of asthma (Table 4), only shorter duration of prophylactic treatment was significantly associated with poor knowledge on asthma. In the multivariate analysis (Table 5), shorter duration of prophylactic treatment $(\mathrm{aOR}=2.49 ; 95 \% \mathrm{CI}=1.5,4.13)$ and education below Ordinary Level $(\mathrm{aOR}=2.48 ; 95 \% \mathrm{CI}=1.59,3.86)$ remained significant. 
Table 4. Association of the caregivers' knowledge on asthma with selected characteristics of asthma of their children $(N=577)$

\begin{tabular}{|c|c|c|c|c|c|c|}
\hline \multirow{3}{*}{ Characteristics of asthma } & \multicolumn{4}{|c|}{ Knowledge on asthma } & \multirow{3}{*}{$\begin{array}{c}\text { Odds Ratio } \\
95 \% \mathrm{CI}\end{array}$} & \multirow{3}{*}{$\begin{array}{c}\text { p } \\
\text { value }^{1}\end{array}$} \\
\hline & \multicolumn{2}{|c|}{ Poor } & \multicolumn{2}{|c|}{ Good } & & \\
\hline & No. & $\%$ & No. & $\%$ & & \\
\hline \multicolumn{7}{|l|}{ Onset of asthma } \\
\hline$\leq 3$ years & 164 & 75.6 & 53 & 24.4 & 1.1 & 0.60 \\
\hline$>3$ years & 265 & 73.6 & 95 & 26.4 & $0.75-1.63$ & \\
\hline \multicolumn{7}{|l|}{ Duration of asthma } \\
\hline$\leq 2$ years & 301 & 75.3 & 99 & 24.8 & 1.16 & 0.45 \\
\hline$>2$ years & 128 & 72.3 & 49 & 27.7 & $0.78-1.73$ & \\
\hline \multicolumn{7}{|l|}{ Previous nebulization } \\
\hline No & 17 & 81.0 & 4 & 19.0 & 1.48 & 0.48 \\
\hline Yes & 412 & 74.1 & 144 & 25.9 & $0.49-4.48$ & \\
\hline \multicolumn{7}{|l|}{ Previous hospitalization } \\
\hline No & 166 & 73.5 & 60 & 26.5 & 0.92 & 0.69 \\
\hline Yes & 263 & 74.9 & 88 & 25.1 & $0.63-1.35$ & \\
\hline \multicolumn{7}{|c|}{ Duration of prophylaxis treatment } \\
\hline$\leq 1$ year & 378 & 77.0 & 113 & 23.0 & 2.29 & 0.01 \\
\hline$>1$ year & 51 & 59.3 & 35 & 40.7 & $1.42-3.7$ & \\
\hline \multicolumn{7}{|l|}{ Acute asthma classification } \\
\hline Moderate & 380 & 74.4 & 131 & 25.6 & 1.01 & 0.98 \\
\hline Severe & 49 & 74.2 & 17 & 25.8 & $0.56-1.8$ & \\
\hline \multicolumn{7}{|c|}{ Chronic asthma classification } \\
\hline 1 and 2 & 371 & 74.6 & 126 & 25.4 & 1.31 & 0.31 \\
\hline 3 and 4 & 49 & 69.0 & 22 & 31.0 & $0.77-2.27$ & \\
\hline \multicolumn{7}{|l|}{ Type of hospital admitted } \\
\hline Teaching & 120 & 80.5 & 29 & 19.5 & 1.59 & 0.04 \\
\hline Other hospitals & 309 & 72.2 & 119 & 27.8 & $1.01-2.51$ & \\
\hline
\end{tabular}

${ }^{1} \mathrm{p}$ value at 0.05 significance level 
Table 5. Determinants for poor caregiver knowledge on asthma by multiple regression analysis $(\mathrm{N}=577)$

\begin{tabular}{|c|c|c|c|c|c|c|}
\hline \multirow[b]{2}{*}{ Variables } & \multirow{2}{*}{ B } & \multirow{2}{*}{ SE } & \multirow{2}{*}{ OR } & \multicolumn{2}{|c|}{$95 \% \mathrm{CI}$} & \multirow[t]{2}{*}{ p value } \\
\hline & & & & Lower & Upper & \\
\hline Admitted to a teaching hospital & 0.38 & 0.24 & 1.46 & 0.91 & 2.36 & 0.11 \\
\hline Caregiver age $<30$ years & 0.36 & 0.23 & 1.43 & 0.91 & 2.25 & 0.12 \\
\hline Duration of prophylaxis treatment $\leq 1$ year & 0.91 & 0.26 & 2.49 & 1.50 & 4.13 & 0.00 \\
\hline Caregiver educated $<\mathrm{O} /$ Levels & 0.91 & 0.23 & 2.48 & 1.59 & 3.86 & $\mathbf{0 . 0 0}$ \\
\hline Constant & -2.13 & 0.29 & & & & 0.00 \\
\hline
\end{tabular}

$\mathrm{B}=$ beta coefficient; $\mathrm{SE}=$ standard error; $\mathrm{OR}=$ odds ratio; $\mathrm{CI}=$ confidence interval; $\mathrm{p}=0.05$ significance level

\section{Discussion}

The mean score for knowledge on asthma was $20.63(\mathrm{SD}=4.42)$ ranging from 7 to 30 . Among the caregivers, only 208 (36\%) had good knowledge on asthma. In a study done in Spain (9), the average knowledge score was $18.5(\mathrm{SD}=3.7)$ out of 31 which is similar to the current study. Yet in another study (10) using the same questionnaire as in the study in Spain (10). The mean scores were observed to be as low as $14.9,11.25$ and 14.5 for teachers, adolescents without asthma and adolescents with asthma, respectively. A study in an emergency department (11) assessing the patients' knowledge, the items on general facts about asthma, the role of medications and environmental controls/triggers were correctly answered by an average of $75 \%$ of the respondents. Identification of common two symptoms of asthma was more than $77.8 \%$ in the current study and closely resembled the $75 \%$ of a similar finding in a study in USA(11).

In the current study, identification of triggering factors was relatively high related to change of weather $(95.5 \%)$, smoking in the house $(88.4 \%)$, burning mosquito coils $(84.9 \%)$ and viral infection $(74.7 \%)$ and was lowest for emotions $(40.2 \%)$. In another study, higher percentage of respondents (95.1\%) understood that their smoking could make their children's asthma worse (11). A similar study found $94-99 \%$ of caregivers were aware of common triggers for asthma exacerbation like upper respiratory infection, weather change and allergens (12). A study in India found parents were knowledgeable on respiratory tract infections (87\%), winter climate (31.3\%), dust (70\%) and smoke $(63 \%)$ as triggering factors for asthma (13). In the study in Lebanon, caregivers identified dust $(61 \%)$, indoor smoking $(51 \%)$ and viral infections $(17 \%)$ as triggering factors for asthma yet these figures were low compared to the other studies (14). In the current study, only $35.4 \%$ could name drugs that could be used as a reliever medication with an episode of asthma, in comparison with only $39.2 \%$ answered correctly about the medications that are used in an acute attack (11).

Among the caregivers, only $33.4 \%$ knew that inhaled drugs have fewer side effects than oral medications and $75.4 \%$ thought they are not good for children if taken for a longer duration. A study by Meyer and colleague revealed that $50 \%$ thought inhaled steroids are addictive and not be used for long duration (11). Similarly, according to the study in Lebanon, $56 \%$ were concerned about side effects of inhalers (14). Furthermore, the study by Bryant (4) found a higher percentage $(73.5 \%)$ of caregivers denying that asthmatic children become addicted to their medication. The vast majority $(82.6 \%)$ of caregivers stated that children with frequent asthma symptoms should be given preventive treatment; a closer figure was observed by Rastogi et al, in which $87.4 \%$ caregivers stated routine inhaler steroids were helpful to control asthma (12).

After controlling the confounding effects, caregivers educated less than $\mathrm{O} /$ Levels and children under prophylaxis treatment for less than one year were 
identified as significant determinants for poor knowledge on asthma. In concurrence, caregivers with a higher level of education showed better knowledge about asthma in two studies $(11,15)$, highlighting that inadequate literacy is a barrier to asthma knowledge and self-care. Similarly, in Nigeria, caregivers with postsecondary education had a significant association with good knowledge on asthma (16). Since education enables to improve reading, listening and remembering the once learned facts, the credibility of the finding is high.

In the current study, the caregivers of children with prophylaxis treatment for less than one year were more likely to have poor knowledge. It could be that children who had long-term prophylaxis treatment were more likely to have severe disease even with controller drugs. Therefore, the caregivers have more experience on medical encounters, and thereby many chances of gaining knowledge on the disease. Contradictory to the current study, respondents with mild, intermittent or persistent asthma had significantly better knowledge than respondents with moderate or severe asthma when severity was classified by night-time symptoms (11).

Most commonly used study setting among the comparative studies were hospital paediatric wards (12$13,16)$, except in one study in which the emergency department was used (11). Another common setting was schools $(5,7,10,14)$. Mostly used study instrument type was self-administered questionnaires. Although this is not perfect for a study population with a diverse educational background, in the current study, only $2.1 \%$ of the caregivers had education for no more than five years.

The poor knowledge on primary and secondary preventive methods may persuade the severity of asthma which prolong the suffering period as well. Ultimately, this may affect the performance in school as well as increase the household and hospital cost for managing the disease. Further, the knowledge on some individual items of the questionnaire especially on medications was poor where most of the caregivers scored less than $50 \%$. Therefore, provision of health education, especially emphasizing the knowledge which aims to modify the current practices of the caregivers would be more appropriate. The majority of caregivers in the study sample had good educational level. Therefore, the generalisation of the findings to other districts should be done with caution.

\section{Conclusions \& Recommendations}

In conclusion, $64 \%$ of caregivers of asthmatic children had poor knowledge on asthma. The caregivers not being educated up to $\mathrm{O} /$ Levels and shorter duration of prophylactic treatment were associated with poor knowledge on asthma. We recommend providing frequent and comprehensive health education on both primary and secondary preventive aspects on asthma to caregivers during the hospital stay and at follow-up visits.

\section{Public Health Implications}

There was a knowledge gap on the primary and secondary preventive methods related to asthma among caregivers, especially on medications. Provision of health education emphasizing on the aspects lacking knowledge, which aims to modify the current practices of the caregivers could be more appropriate especially poorly educated caregivers with children on shorter duration of prophylaxis.

\section{Author Declarations}

Competing interests: The authors declare that they have no competing interests.

Ethics approval and consent to participate: Ethics clearance for the study was obtained from the Ethics Review Committee of the Faculty of Medicine, University of Kelaniya. Administrative clearance for the data collection was obtained from Regional Director of Health Services, Gampaha District.

Funding: Self-funded

Acknowledgements: We are grateful to the Postgraduate Institute of Medicine, University of Colombo and the data collectors for the study.

Author contributions: NP designed the study, coordinated data collection, performed the statistical analysis and helped to draft the manuscript. CA designed the study, performed the statistical analysis, interpreted the data and drafted the first version of the manuscript. Both read and approved the final manuscript. 


\section{References}

1. The Global Asthma Report 2014. Available from: http://www.globalasthmareport.org/ 2014/about/executive.php.

2. Medical Statistics Unit. Sri Lanka Annual Health Bulletin 2006. Colombo: Ministry of Health, 2006. Available from: http://ghdx.healthdata.org/record/srilanka-annual-health-bulletin-2006

3. WHO. World Health Organization Fact Sheet Asthma. Available from: http://www.who.int/news-room/factsheets/detail/asthma

4. Bryant-Stephens T, Li Y. Community asthma education program for parents of urban asthmatic children. Journal of the National Medical Association 2004; 96(7): 954-960.

5. Butz A, Pham L, Lewis L, Lewis C, Hill K, Walker J, et al. Rural children with asthma: impact of a parent and child asthma education program. Journal Asthma 2005; 42(10): 813-821.

6. Živković Z, Radić S, Cerović S, Vukašinović Z. Asthma School Program in children and their parents. World Journal of Pediatrics 2008; 4(4): 267-273.

7. Gunathunga CK. Assessment of some components of quality of patient care in general medical wards in National Hospital of Sri Lanka. MSc Dissertation (Community Medicine). Colombo: Postgraduate Institute of Medicine, 1998.

8. Ministry of Health. Management Guidelines for Paediatric Asthma. Health Sector Development Project. Colombo: Ministry of Health \& College of Paediatricians, 2008.
9. Leonardo Cabelloa MT, Oceja-Setienb E, García Higueraa L, Caberoa MJ, Pérez Belmontea E, GómezAcebo I. Assessment of parental asthma knowledge with the Newcastle Asthma Knowledge Questionnaire. Pediatrics Primary Care 2013; 15: 117-126.

10. Gibson PG, Henry RL, Vimpani GV, Halliday J. Asthma knowledge, attitudes, and quality of life in adolescents. Archives of Disease in Childhood 1995; 73(4): 321-326.

11. Meyer IH, Sternfels P, Fagan JK, Copeland L, Ford JG. Characteristics and correlates of asthma knowledge among emergency department users in Harlem. Journal of Asthma 2001; 38(7): 531-539.

12. Rastogi D, Madhok N, Kipperman S. Caregiver asthma knowledge, aptitude, and practice in high healthcare utilizing children: effect of an educational intervention. Pediatric Allergy, Immunology and Pulmonology 2013; 26(3): 128-139.

13. Gajanan G, Padbidri VSandeep, Chaudhury A. Assessment of knowledge and attitude of parents towards the allergy and bronchial asthma in their children. International Journal of Medicine and Public Health. 2016; 6(3): 121-125.

14. Zaraket R, Al-Tannir MA, Bin Abdulhak AA, Shatila A, Lababidi H. Parental perceptions and beliefs about childhood asthma: a cross-sectional study. Croatian Medical Journal 2011; 52(5): 637-643.

15. Williams MV, Baker DW, Honig EG, Lee TM, Nowlan A. Inadequate literacy is a barrier to asthma knowledge and self-care. Chest 1998; 114(4): 1008-1015.

16. Kuti BP, Omole KO. Factors associated with caregivers' knowledge about childhood asthma in Ilesa, Annals of Nigerian Medicine 2016; 10:30-36. 